Expression of Concern

\title{
Expression of Concern: Experimental Study of Thoracoabdominal Injuries Suffered from Caudocephalad Impacts Using Pigs
}

\author{
Applied Bionics and Biomechanics \\ Received 28 November 2019; Accepted 29 November 2019; Published 15 December 2019 \\ Copyright (c) 2019 Applied Bionics and Biomechanics. This is an open access article distributed under the Creative Commons \\ Attribution License, which permits unrestricted use, distribution, and reproduction in any medium, provided the original work \\ is properly cited.
}

Applied Bionics and Biomechanics would like to express concern with the article titled "Experimental Study of Thoracoabdominal Injuries Suffered from Caudocephalad Impacts Using Pigs" [1].

Concerns have been raised regarding the ethical standards of the reported research, which we feel require further investigation. These investigations will aim to determine whether the research adheres to the recommendations of the Guide for the Care and Use of Laboratory Animals of the National Institutes of Health, as stated in the manuscript.

The authors have been informed of this notice and the on-going investigation.

\section{References}

[1] S. Guan, Z. Liao, H. Xiang et al., "Experimental Study of Thoracoabdominal Injuries Suffered from Caudocephalad Impacts Using Pigs," Applied Bionics and Biomechanics, vol. 2018, Article ID 2321053, 10 pages, 2018. 


\title{
Experimental Study of Thoracoabdominal Injuries Suffered from Caudocephalad Impacts Using Pigs
}

\author{
Sishu Guan, ${ }^{1}$ Zhikang Liao, ${ }^{2}$ Hongyi Xiang, ${ }^{2}$ Xiyan Zhu, ${ }^{2}$ Zhong Wang, ${ }^{1}$ Hui Zhao $\mathbb{D},{ }^{2}$ \\ Peng Liu $\mathbb{D}^{1}{ }^{1}$ and Xinan Lai ${ }^{2}$ \\ ${ }^{1}$ Department of Spine Surgery, Daping Hospital, Third Military Medical University, Chongqing 400042, China \\ ${ }^{2}$ State Key Laboratory of Trauma; Burns \& Combined Wound, Institute for Traffic Medicine, Third Military Medical University, \\ Chongqing 400042, China
}

Correspondence should be addressed to Hui Zhao; box.zhaohui@163.com and Peng Liu; liupengd@163.com

Received 7 December 2017; Revised 26 February 2018; Accepted 12 March 2018; Published 10 May 2018

Academic Editor: Yong Peng

Copyright (c) 2018 Sishu Guan et al. This is an open access article distributed under the Creative Commons Attribution License, which permits unrestricted use, distribution, and reproduction in any medium, provided the original work is properly cited.

\begin{abstract}
To know the caudocephalad impact- (CCI-) induced injuries more clearly, 21 adult minipigs, randomly divided into three groups: control group $(n=3)$, group I $(n=9)$, and group II $(n=9)$, were used to perform the CCI experiments on a modified deceleration sled. Configured impact velocity was $0 \mathrm{~m} / \mathrm{s}$ in the control group, $8 \mathrm{~m} / \mathrm{s}$ in group I, and $11 \mathrm{~m} / \mathrm{s}$ in group II. The kinematics and mechanical responses of the subjects were recorded and investigated. The functional change examination and the autopsies were carried out, with which the injuries were evaluated from the Abbreviated Injury Scale (AIS) and the Injury Severity Score (ISS). The subjects in group I and group II experienced the caudocephalad loading at the peak pelvic accelerations of $108.92 \pm 58.87 \mathrm{~g}$ and $139.13 \mathrm{~g} \pm 78.54 \mathrm{~g}$, with the peak abdomen pressures, $41.24 \pm 16.89 \mathrm{kPa}$ and $63.61 \pm 65.83 \mathrm{kPa}$, respectively. The injuries of the spleen, lung, heart, and spine were detected frequently among the tested subjects. The maximal AIS (MAIS) of chest injuries was 4 in group I and 5 in group II, while both the MAIS of abdomen injuries in group I and group II were 5 . The ISS in group II was $52.71 \pm 6.13$, significantly higher than in group I, $26.67 \pm 5.02(p<0.05)$. The thoracoabdomen CCI injuries and the mechanical response addressed presently may be useful to conduct both the prevention studies against military or civilian injuries.
\end{abstract}

\section{Introduction}

The injuries induced by caudocephalad impacts (CCI) frequently occurred in military vehicles, for example, underbelly blasts (UBB), which have led to large numbers of injuries and deaths [1-3]. Some civilian accidents, such as helicopter crashes and falls [4-11], resulted in also so many casualties owing to the CCI. For example, helicopters are being widely used worldwide nowadays due to their excellent motorization, with an estimated incidence of 2.5 helicopter crashes per 100,000 flying hours [9], and the mortality rate of the injuries involved in helicopter crashes was up to 59\% [5]. Falls contributed to approximately 35 million disabilities or adjusted life years annually, showing an increase trend [11].

Thoracoabdomen is vulnerable to the CCI, and the CCIinduced thoracoabdominal injuries were reported frequently, with potential disaster outcomes [12-16]. As compared to the thoracoabdomen injuries induced by the horizontal impacts, such as anterior-posterior or lateral, remarkable discrepancies existed in injury mechanism, injury characteristics, and injury tolerance from the injuries by the CCI. In the past decades, the reported researches with regard to CCI-related injuries were done by retrospectively analyzing the injuries or deaths involved in the military or civilian scenarios [12-16] or performing the impact experiments with a dummy or cadaver [17-22]. The results have played key roles in understanding the injury mechanisms and evaluating the injury response for the CCI injuries, that is, fractures for the spine. However, the studies using postmortem human surrogates (PMHS) or finite element analysis (FEA) hardly produced successfully the injuries by thoracoabdominal organs frequently reported in military or civilian scenarios, 


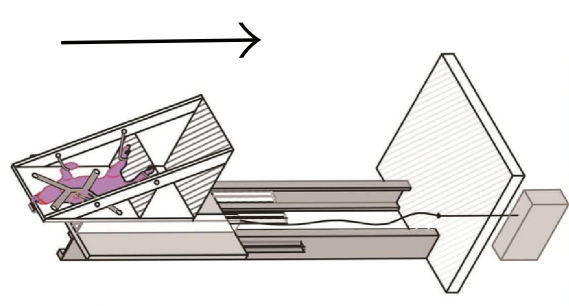

(a)

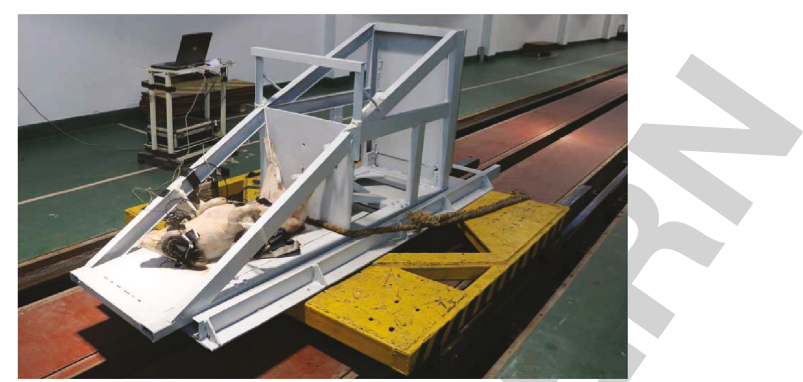

(b)

FIGURE 1: The schematic diagram and photograph of the installation. (a) Schematic diagram. The setup comprises a sled with three thin steel pipes, a horizontal seat assembly fixed on the carriage, rail, rigid wall, and traction control system. When the thin steel pipes collide with the rigid wall, the sled stops and the carriage continues to move forward and impact with the rigid wall, and finally the buttock of the pig experienced a high caudocephalad acceleration loaded from the seat. (b) The setup photograph. The pig lays in a supine position on the carriage, and the setup was ready for the CCI.

particularly hemorrhage, and as a result, the injuries led by the CCI remained unclear. Furthermore, there still has been a paucity of experimental data concerning the thoracoabdominal CCI injuries until now, especially with animals.

In order to more clearly address the thoracoabdomen CCI-induced injuries, adult minipigs, whose anatomical structures of thoracoabdominal organs and physiological changes of the impact injury are similar to human body to some extent [23], were employed as a surrogate model of human body in the present study.

\section{Material and Methods}

This study was carried out strictly following the recommendations in the Guide for the Care and Use of Laboratory Animals of the National Institutes of Health. The protocol was approved by the Animal Ethics Committee of the Third Military Medical University (Permit number: 20150402), and great efforts were made to minimize suffering of the experimental animals and cut down the animal number.

2.1. Experimental Setup. A modified deceleration sled was used to mimic the CCI to the animals. Figure 1 illustrates the schematic diagram and photo of the experimental instruments. The setup consists of a horizontally orientated seat assembly, fixed on a carriage designed to slide with respect to the sled. When beginning the test, the sled and carriage were accelerated simultaneously to the configured velocity, and then the sled was stopped by the thin steel pipes as energy absorbers, fitted in front of the sled (with a thickness of $1.5 \mathrm{~mm}$ and a section of $80 \mathrm{~mm} \times 80 \mathrm{~mm}$ ). The carriage continued to move towards the rigid wall along the two rails of " $C$ " shape and stopped by contacting with the rigid wall (Figure 1). A piece of hard rubber, mounted in the frontal of the wall, may avoid the destruction due to a high acceleration that resulted from the impact between the carriage and the rigid wall.

2.2. Animal Preparation. A total of 21 healthy Guizhou Congjiang adult minipigs, weighing $25-30 \mathrm{~kg}$, either male or female, were obtained from the Experimental Animal Center of Daping Hospital, Third Military Medical University,
Chongqing, China. The animals were housed in ventilated rooms and allowed to acclimatize to their surroundings for over 4 days before the test, and good physical conditions were kept for all the animals. All animals were fastened but free of water for $8 \mathrm{~h}$ prior to the tests. The animals were divided into randomly 3 groups: control group $(n=3)$, group I $(n=9)$, and group II $(n=9)$.

After premedication with an intramuscular injection of ketamine $(30 \mathrm{mg} / \mathrm{kg})$ and atropine $(0.1 \mathrm{mg} / \mathrm{kg})$, anesthesia was induced by xylazine hydrochloride $(2 \mathrm{mg} / \mathrm{kg}$, intramuscular injection) and maintained by pentobarbital $(10 \mathrm{mg} /$ $\mathrm{kg} / \mathrm{h}$, injecting through ear vein). The animals were tracheotomised with a tracheotomy cannula where respiratory rate was adjusted to obtain arterial $\mathrm{PCO}_{2}$ between 35 and $45 \mathrm{mmHg}$. Body temperature was maintained between $37^{\circ} \mathrm{C}$ and $39^{\circ} \mathrm{C}$ with a blanket. Cardiocirculatory and respiratory parameters were monitored continuously. Before the impact, all animals received an intravenous injection of $2 \mathrm{mg} / \mathrm{kg}$ carprofen to prevent pain. After stable anesthesia, artificial ventilation was shopped for the whole process.

Two sensors were used to record in vivo the mechanical response during the test. One was an acceleration sensor (7287-1-300, Endevco, USA; acceleration range: 0-2000 g), and the other was a pressure sensor (CYG41000, Dechen, China; pressure range $0-500 \mathrm{kpa}$ ). A metal block was mounted on the pelvis with several screws, and the acceleration sensor was glued to the block to measure the acceleration along the caudocephalad direction. The pressure sensor was inserted into a balloon filled with the liquid and placed under the liver to measure the abdomen pressure. The installation of the sensors is shown in Figure 2.

2.3. The Experimental Procedure. The anesthetized pig was fastened to seat with a 4-point hardness to avoid the throwing during experiencing the impact, in which the buttock of the subject contacted the rigid seat prior to the test, and the limbs were loosely fixed in the frame, mimicking a "sitting" posture (Figure 1), so that the loading may be acted on the buttock of the subject along the caudocephalad direction. Impact velocity of the sled was configured as $8 \mathrm{~m} / \mathrm{s}$ in group I and $11 \mathrm{~m} / \mathrm{s}$ in group II, respectively. The animals in the control group experienced the same test procedure in which the 


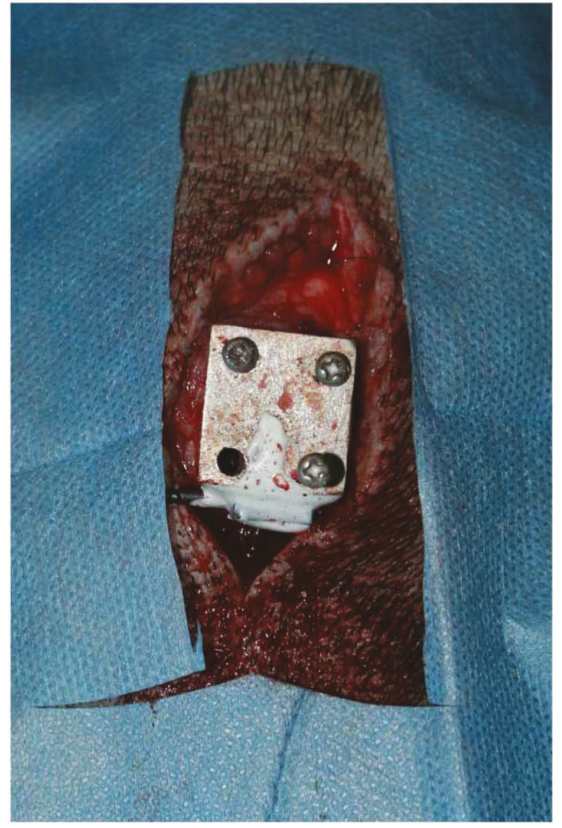

(a)

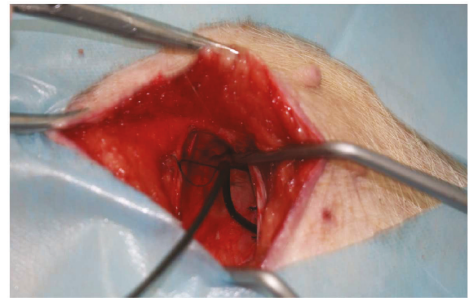

(b)

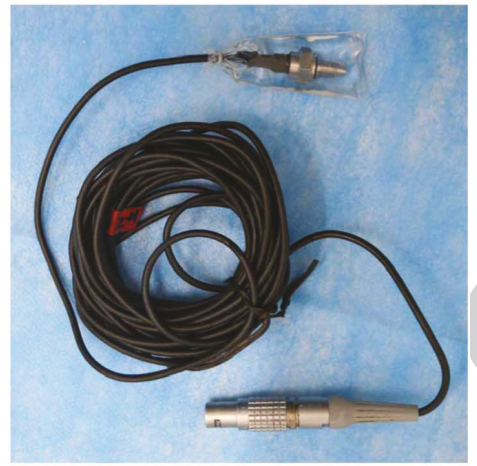

(c)

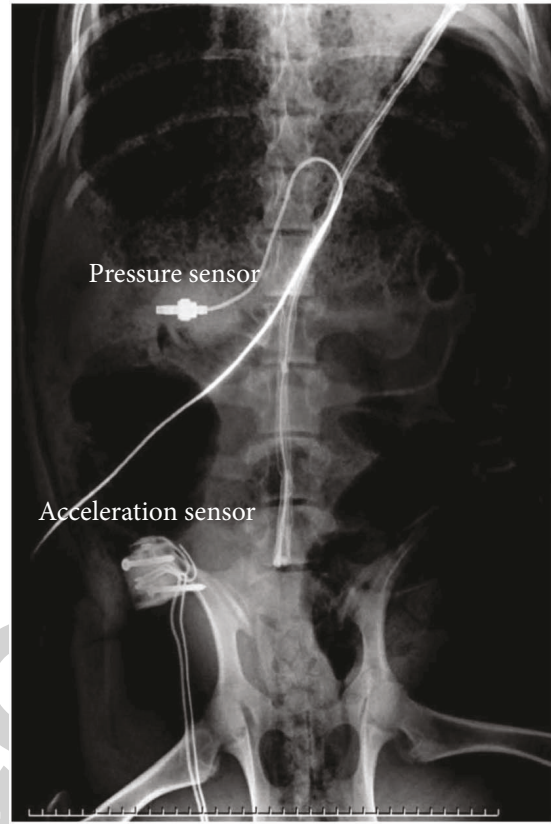

(d)

Figure 2: The installation of the sensors. (a) The operation photograph of the acceleration sensor installation. The sensor was glued to a metal block that was mounted on the pelvis via screws. (b) The operation photograph of the pressure sensor installation. The laparotomy was done, and the sensor was placed under the liver. (c) The photograph of the pressure sensor. The sensor was inserted into a balloon filled with liquid. (d) The X-ray photograph, in which the sensors were indicated with arrows.

impact speed was defined as $0 \mathrm{~m} / \mathrm{s}$. When the experiment was initiated, the sled was accelerated from the starting position, running along the rail with a length of about $80.0 \mathrm{~m}$, and stopped by the contact between the thin-wall pipes and rigid wall. The impact velocity of the sled was determined with a customer speed dosimeter. The whole course of the CCI was recorded by a high-speed video camera (Phantom V4.3, Vision Research), at 1000 frames per second.

2.4. Injury General Examination. Heart rate (HR), respiratory rate (RR), blood pressure (BP), and arterial blood gas analyses (ABGA, portable blood gas analyzer: i-STAT, Princeton NJ, USA) of all the subjects were recorded within $6 \mathrm{~h}$ postinjury at an interval of $1 \mathrm{~h}$, in which the phase of $0 \mathrm{~h}$ referred to the immediate record after the test.

2.5. Injury Pathological Examination. Full-body CT scans were performed randomly for two pigs in group I and group II pre- and postinjury, to detect injury to the skeleton. The animals were sacrificed $6 \mathrm{~h}$ postinjury, and then considerable autopsies were carried out. The tissue at the injured location was obtained and prepared for microscopic observation, and the histopathological alternations were recorded. The autopsies were done immediately once the animals died. The injuries of the subjects were evaluated according to the Abbreviated Injury Scale 2005 (AIS-2005) [24], and the maximal AIS (MAIS) of each anatomical region was used to calculate the Injury Severity Score (ISS).

2.6. Statistical Analysis. ABGA and ISS were presented as mean \pm SD and were analyzed using SPSS ${ }^{\circledR} 19.0$ software.
The differences of the acquired histopathological alternations in tested animals were tested using one-way analysis of variance (ANOVA). Comparison of AIS in groups I and II was conducted using chi-square test, and the ISS comparison between groups I and II was done using $t$-test. A value of $p<0.05$ was considered statistically significant.

\section{Results}

The determined impact speeds of groups I and II were $8.21 \pm 0.13 \mathrm{~m} / \mathrm{s}$ and $10.69 \pm 0.41 \mathrm{~m} / \mathrm{s}$. The peak accelerations of the sled were $21.27 \pm 1.70 \mathrm{~g}$ in group I and $34.07 \pm 13.56 \mathrm{~g}$ in group II. Figure 3 shows the kinematics of the subjects during crashing from a series of images derived from the high-speed camera, in which the maximal height $(\mathrm{MH})$ was used to estimate the bending of the thoracolumbar spine, as shown in Figure 3(c). The $\mathrm{MH}$ in group II was significantly higher than that in group I $(15.01 \pm 0.98 \mathrm{~cm}$ versus $11.27 \pm 1.67 \mathrm{~cm}, p<0.05)$.

The peak acceleration recorded on the subject pelvis in group II was $139.13 \pm 78.54 \mathrm{~g}$, significantly higher than that in group I, $108.92 \pm 58.87 \mathrm{~g}(p<0.01)$, while the peak pressure of the abdomen in group II, $63.61 \pm 65.83 \mathrm{kPa}$, was significantly higher than that in group I, $41.24 \pm$ $16.89 \mathrm{kPa}(p<0.05)$. Figure 4 shows the corridor curves of the caudocephalad accelerations and the abdomen internal pressure.

All the animals in group I survived, while in group II, 5 died of the mass bleeding within $2 \mathrm{~h}$ posttest, and 1 died immediately after the impact. Among all the subjects, HR and RR speeded up immediately after the impact and lasted 


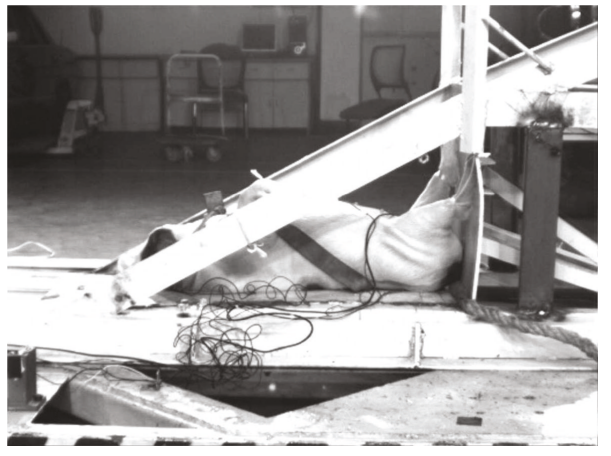

(a)

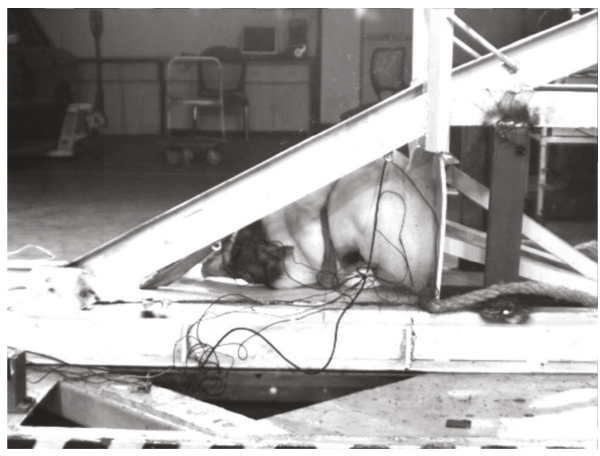

(c)

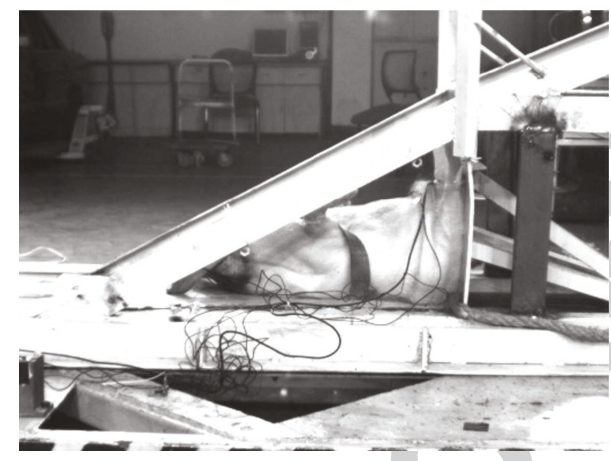

(b)

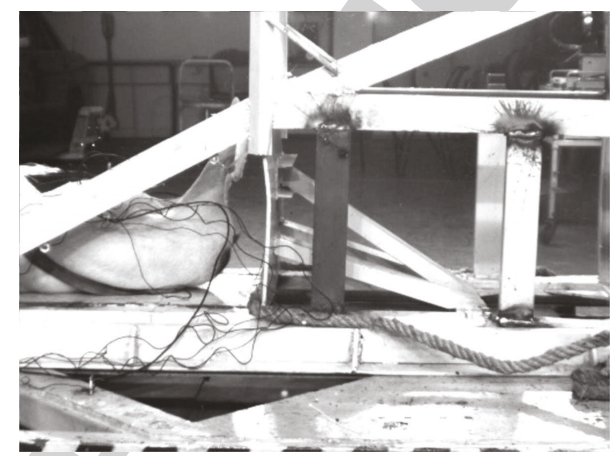

(d)

Figure 3: The kinematics of the pig during the CCI. (a) T0: the sled is hitting against the wall but the pig was motionless to the carriage. (b) T1: the pig showed maximal deformation of the abdomen due to severe compression of the torso along the caudocephalad direction. (c) T2: peak point of the spine bending. The maximal height $(\mathrm{MH})$ indicated with the arrows refers to the distance between the peak point of the spine bending and the deck of carriage. (d) T3: the spine returned to normal form.

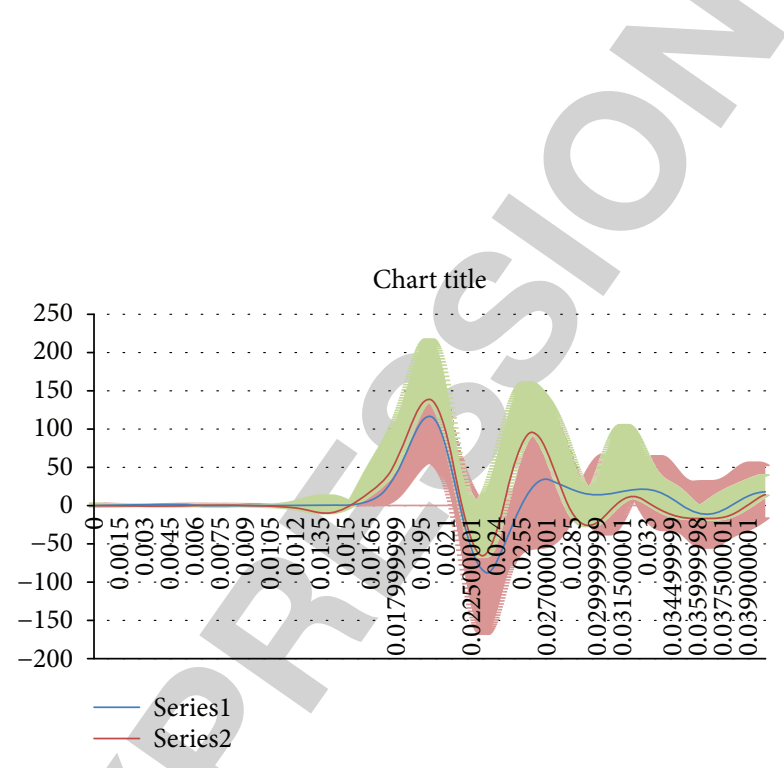

(a)

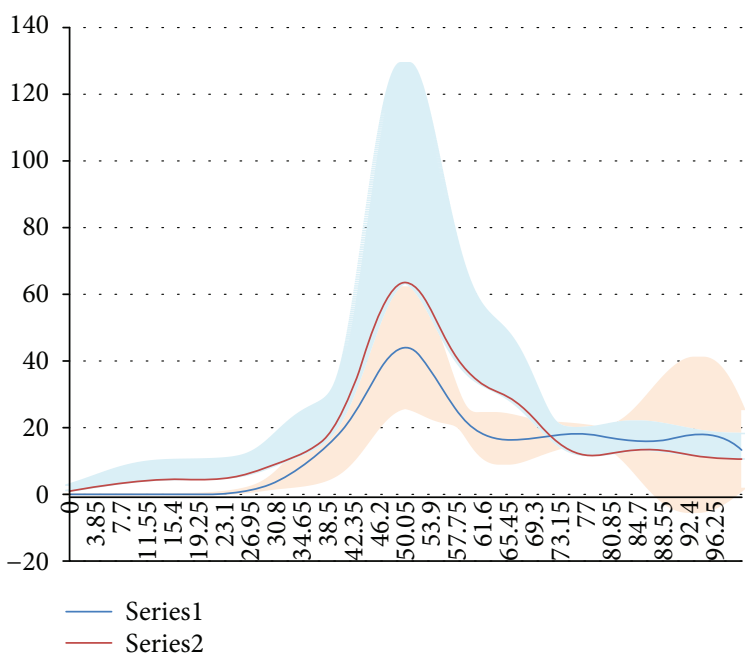

(b)

FIgURE 4: The corridor curves of the acceleration and pressure. The corridor of the acceleration (a) and the pressure (b) was showed, in which the acceleration and the pressure were indicated with different colors, with black referring to the data in group I and red in group II.

for a few minutes. Subsequently, $\mathrm{HR}$ and RR in group I recovered to normal level, as compared to those in the control group, while HR and RR in group II kept at higher levels. $\mathrm{BP}$ in group I decreased rapidly after the impact and then remained stable at $40 \%$ of normal levels, in which BP in group II dropped to $10-20 \%$ of normal levels. Oxygenation parameters did not shift in the control group. The $\mathrm{PCO}_{2}$, $\mathrm{PO}_{2}, \mathrm{pH}$, and $\mathrm{HCO}_{3-}$ in group I indicated a decreasing trend, 


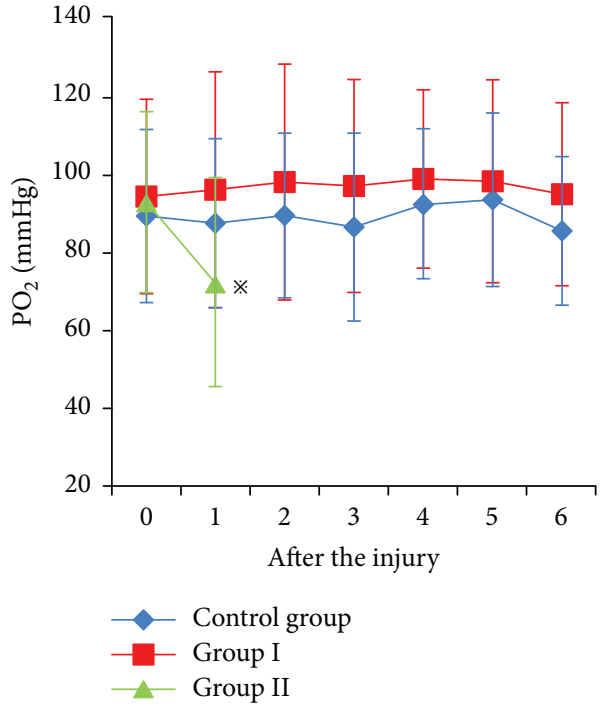

(a)

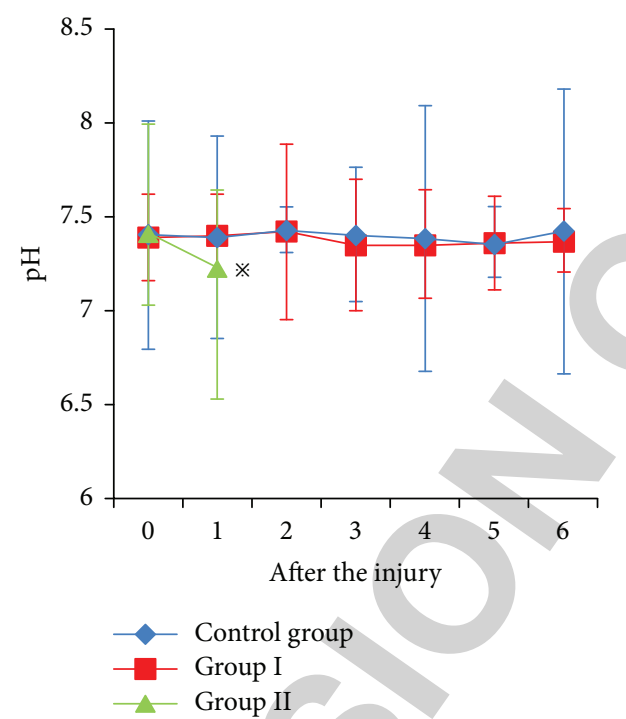

(c)

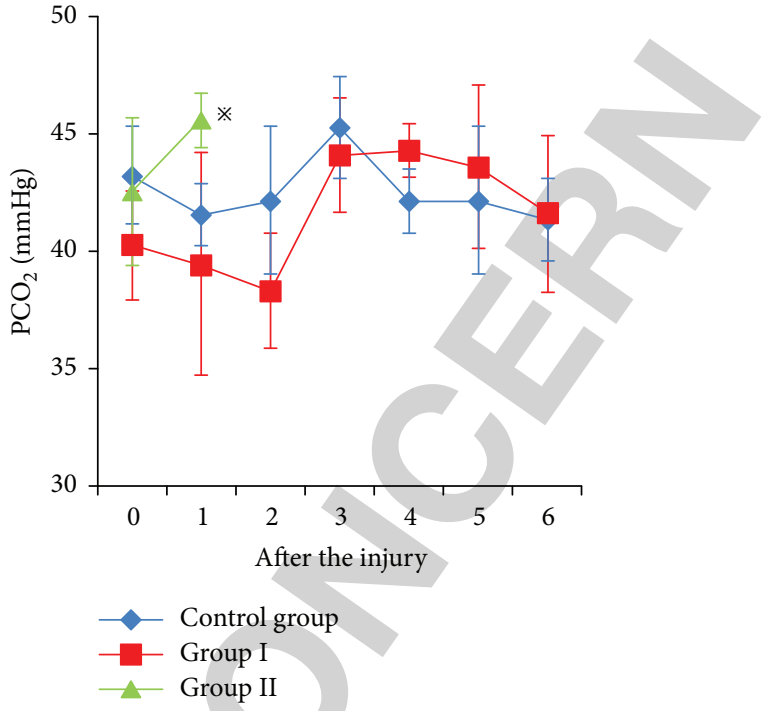

(b)

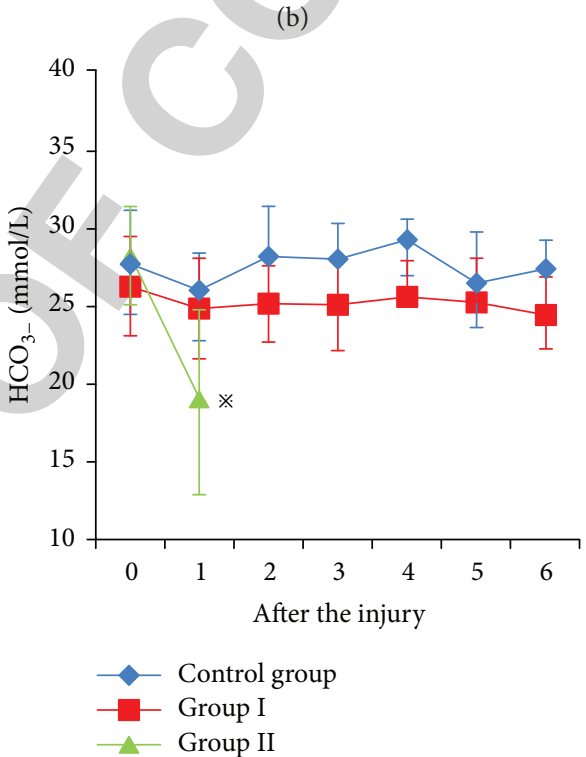

(d)

Figure 5: Arterial blood gas analysis. (a) $\mathrm{PO}_{2}$, (b) $\mathrm{PCO}_{2}$, (c) $\mathrm{pH}$, and (d) $\mathrm{HCO}_{3}$ are detected in all three groups. ${ }^{*}$ Deterioration of ABGA $\left(\mathrm{PCO}_{2}, \mathrm{PO}_{2}, \mathrm{pH}\right.$, and $\left.\mathrm{HCO}_{3-}\right)$ at $1 \mathrm{~h}$ compared with baseline and control group, $p<0.05$.

as compared to those in the control group. In group II, the value of ABGA showed a deterioration at $1 \mathrm{~h}$, as compared to that in the control group, but did not reach the criteria of respiratory failure (Figure 5).

The common thoracoabdomen injuries from the autopsies included fractures, contusion, laceration, bleeding, and hemorrhage. The injured thoracoabdominal organs, that is, the spleen, lung, heart, and kidney, were observed commonly; however, the rate of subendocardial hemorrhage $(\mathrm{SEH})$ in group I (4/9) was higher, as compared to that in group II (1/9). Furthermore, rib fractures and liver injuries have never been detected from the tested pigs. Figure 6 shows the typical injuries to the thoracoabdomen organs, Figure 7 exhibits the fractures in the thoracolumbar spine and pelvis, and Figure 8 illustrates the heart injuries in gross and microscopic observation.
The MAIS of chest injuries was 4 in group I and 5 in group II, while 8 in group I and 9 in group II experienced the MAIS 5 abdomen injuries. There was a significant distribution discrepancy in MAIS between both groups $(p<0.05)$, as shown in Table 1. The ISS of group II, 52.71 \pm 6.13 , was significantly higher than that of group I, $26.67 \pm 5.02$ $(p<0.05)$.

\section{Discussion}

For the CCI-induced thoracoabdomen injuries, especially at a high loading rate, which frequently occurred in the military or civilian scenarios, the authors presumed that there may be two ways to transmit the vertical loading: one is the bone, and the other is the soft tissues, that is, thoracoabdomen muscles and organs, and the energy transmission may result in the 


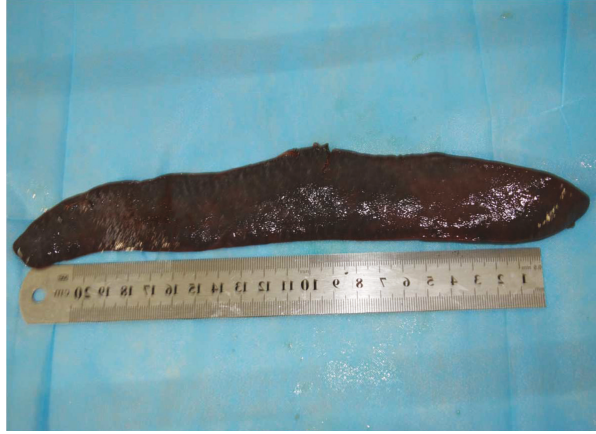

(a)

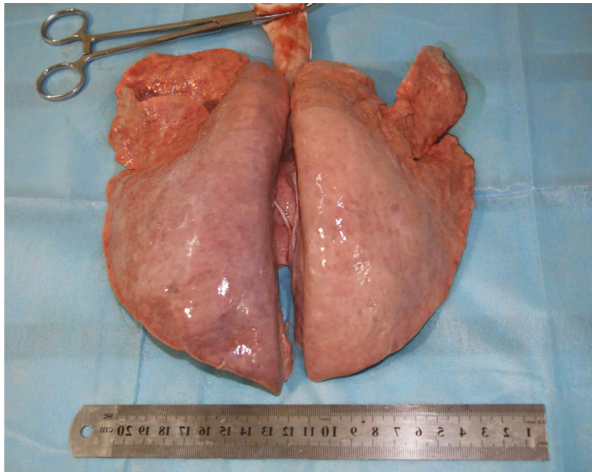

(c)

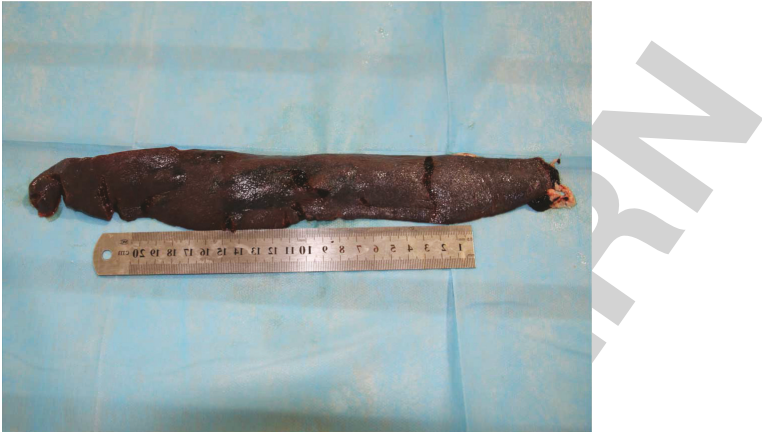

(b)

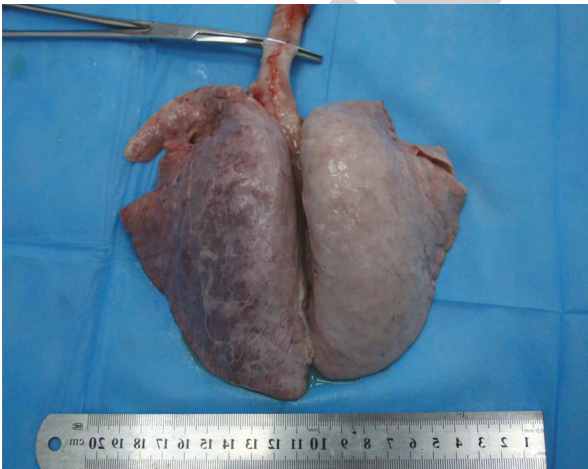

(d)

FIgURE 6: Typical injuries of the thoracoabdominal organs of the pigs that sustained CCI. (a) Ruptures of the spleen in group I, with 2-3 small wounds in the spleen indicated; (b) multiple wounds of the spleen in group II in which the wounds were more wider and deeper than those of group I; (c) there was no obvious damage to the lung of the pigs in group I after the impact; (d) diffuse hemorrhage of the lung of the pig in group II, in which the lamellar hemorrhage was observed.

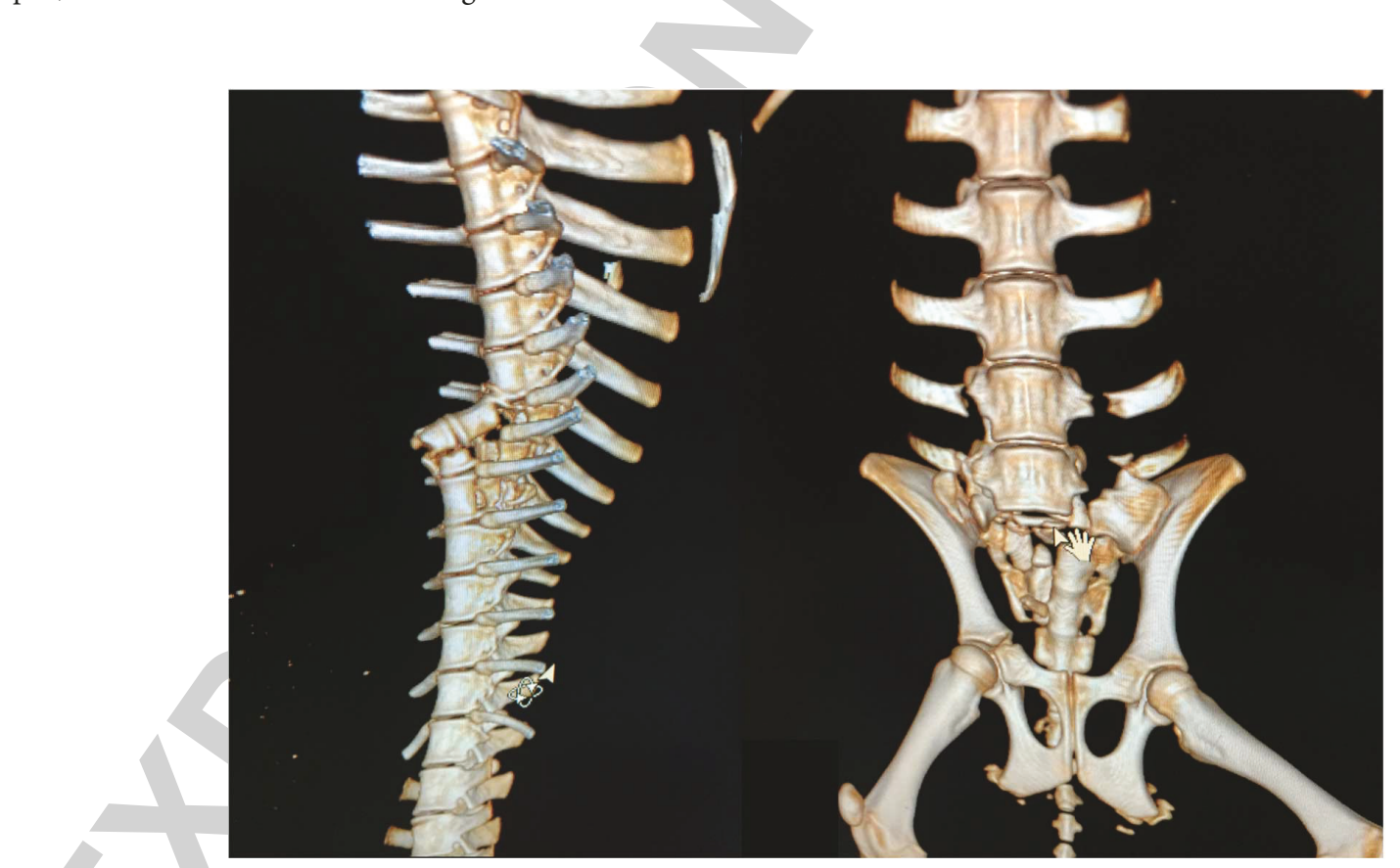

FIGURE 7: 3D CT reconstruction of the spine and pelvic fractures.

injuries to the torso. Among the previously reported literature, most studies were done by carrying out experiments with a dummy or cadaver $[16,17,20-22]$, in which the spine fractures have been validated from the published studies, while the response of the transmission along the soft tissue seldom was reported. In the present study, the CCI 


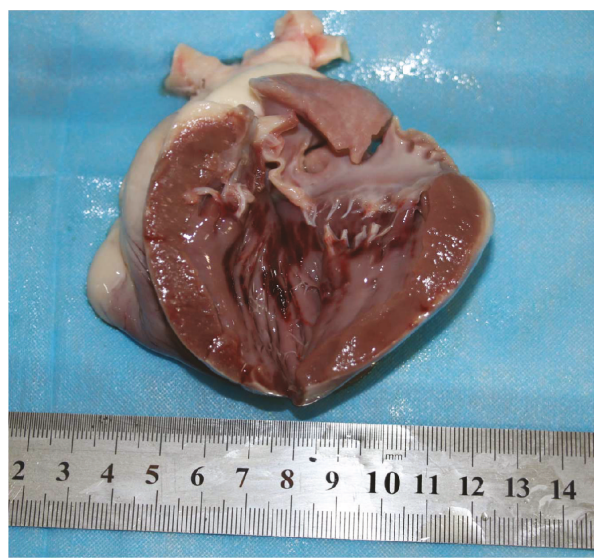

(a)

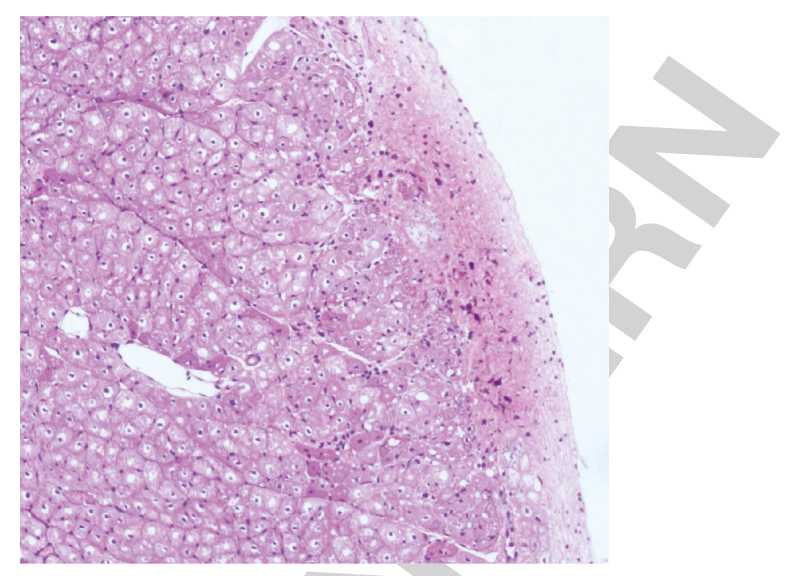

(b)

FIGURE 8: Subendocardial hemorrhage in gross and microscopic observation. (a) Subendocardial hemorrhage in gross observation in group I. (b) Subendocardial hemorrhage under microscopic observation in group I $(\mathrm{HE} \times 100)$.

TABLE 1: The AIS distribution of the injuries of the animals.

\begin{tabular}{lcccccccc}
\hline \multirow{2}{*}{ Position } & \multicolumn{4}{c}{ Group I AIS } & \multicolumn{4}{c}{ Group II AIS } \\
& 0 & $1 \sim 2$ & $3 \sim 4$ & $5 \sim 6$ & 0 & $1 \sim 2$ & $3 \sim 4$ & $5 \sim 6$ \\
\hline Head & - & - & 0 & 0 & - & - & 0 & 0 \\
Neck & 9 & 0 & 0 & 0 & 9 & 0 & 0 & 0 \\
Chest & 7 & 1 & 1 & 0 & 1 & 0 & 8 & 0 \\
Abdomen & 0 & 0 & 8 & 1 & 0 & 0 & 0 & 9 \\
Spine & 0 & 9 & 0 & 0 & 0 & 0 & 3 & 6 \\
Pelvis & 0 & 0 & 9 & 0 & 0 & 0 & 0 & 9 \\
\hline
\end{tabular}

experiments were performed using adult minipigs at the different impact speeds, through which the thoracoabdomen injuries caused by the CCI and the response were studied.

The spine plays a key role in supporting the torso and transporting the loading along the vertical direction. The thoracolumbar spinal curvature changes from kyphotic to lordotic [25], while the thoracolumbar junction is particularly susceptible to fracture as it is under significant biomechanical stress due to the articulation of the relatively rigid thoracic segment, through its connections to the ribcage and sternum, with the more mobile lumbar region [26]. For example, it was reported that in aviation accidents, very few fractures occurred at the cranial and caudal levels, for example, $2 \%$ of fractures in the cervical spine, $78 \%$ of fractures in the thoracic spine, and $19 \%$ of fractures in the lumbosacral spine [27]. In the experiment, all subjects sustained the thoracolumbar fractures, and with an increase of the impact speed, the spine fractures became worse, affecting the stability of the spine. It can be concluded that the CCI-induced spine injuries (Figure 7) were associated with not only the compression but also the bending (Figure 3).

The review of Bailey et al. [28] suggested that among the experiments in studying pelvis and lower-extremity injuries using intact cadavers, the speed of a seat plate of a military vehicle subjected to the UBB may be up to about $12 \mathrm{~m} / \mathrm{s}$, while for the regulation of fall tests of a helicopter, the test speed was configured at $8 \mathrm{~m} / \mathrm{s}$ and $12 \mathrm{~m} / \mathrm{s}$. In this study, we found the thoracoabdomen organs sustained severe injuries due to the vertical load transmission, while the severe and critical injuries could be reproduced by the CCI at the impact speed of $8 \mathrm{~m} / \mathrm{s}$ and $11 \mathrm{~m} / \mathrm{s}$. Among the injuries, some remarkable characteristics in injury distribution and pattern for the injured thoracoabdomen organs were represented. In the experiment, the injuries of the thoracoabdomen organs, that is, the spleen, lung, heart, and kidney, were detected, and the injury patterns included contusion, laceration, and bleeding. The injuries observed in the study were coincident with those reported upon the autopsies for the victims involved in some accidents $[29,30]$. However, some thoracoabdomen injuries, that is, rib fractures, aortic tears, cardiac rupture, and liver contusion, reported in the aviation accidents and falls $[29,30]$, were not reproduced in the current experiment. The authors suggest that among the autopsies for the victims, the injuries resulted from not only vertical but also horizontal. To the authors' viewpoint, therefore, the founding was valuable for the forensic worker to delineate the injury cause and distinguish the injuries induced by vertical, frontal, or lateral impact.

According to the study, it was concluded that for the injuries induced by the vertical loading on the buttock, the abdomen injuries were more severe as compared with the chest injuries. Our study showed that the mass bleeding due to the spleen laceration attributed to the death soon without any timely treatment, which means for the CCI injuries, the injury management for the control of bleeding is necessary to reduce the deaths. Kwon et al. [31] suggested that traumatic pelvic fracture patient prognosis needs to be improved through early diagnosis and prompt delivery of aggressive treatments based on rapid identification of abdominal solid organ injuries. However, previous pelvis trauma studies about bleeding control mostly focused on the injuries to the liver rather than the spleen, whereby numerous animal models were developed using pigs [32-39].

Among the abdomen injuries from horizontal impacts, liver injuries were detected frequently. Lau and Viano [40] considered that there were two regions of biomechanical response to blunt hepatic injury at the impact speeds of $>12 \mathrm{~m} / \mathrm{s}$ or $\leq 12 \mathrm{~m} / \mathrm{s}$. Some studies considered that the 
abdomen pressure may be an ideal predictor of liver injuries from horizontal loading [41-44]. From the current experiment, at the impact speed of $10.69 \pm 0.41 \mathrm{~m} / \mathrm{s}$, the abdomen internal pressure was up to $63.61 \pm 65.83 \mathrm{kPa}$, while the subjects in group I and group II did not experience liver injury. It may be concluded from the current study that the spleen is more vulnerable as compared to the liver for the CCI, and as a consequence, the prevention against spleen injuries also be paid a great attention to the CCI.

The lung injuries caused in road traffic accidents were considered traditionally to be associated with the impact speed and chest compression deflection, while in the present study, without any direct impact to the chest, lung injuries occurred frequently, so the authors presumed that the deceleration [45] and pressure changes on the chest [46] induced by the rapid diaphragmatic movement during high vertical loading may contribute to diffused lung injury (Figure 6). Our results showed the lung injuries may rapidly cause the deterioration of respiratory function in the critical injuries.

The CCI could result in heart injuries, that is, $\mathrm{SEH}$, while a high rate of the SEH was found in group I $(4 / 9,44 \%)$, rather than in group II $(1 / 9,11 \%)$. The results suggest that the CCI contributed not only to primary SEH but the CCI-induced injuries may also lead to secondary SEH. Some previous studies concluded that the SEH may be related not only to the exposure to high acceleration [47] but also to brain trauma [48] and hemorrhagic shock [49]. Charaschaisri et al. [50] considered that even minor SEH might have an influence on cardiac function and might be involved in the mechanism of death. Therefore, besides injury prevention against heart injuries, for the injuries sustaining the CCI, the cardiac function should be also in monitor in injury management.

4.1. Limitations. Although the characteristics of the thoracoabdomen injuries induced by the CCI were addressed in the current study, some limitations still exist. Firstly, the CCI mimicking vertical impacts in the present study may ignore the influence of gravity. Secondly, the anatomical structure of pigs in the thoracoabdomen differs from human to some extent, especially for curvature of the spine. Thirdly, the pathological changes of minipigs were observed in the acute stage, while some researchers may concern the secondary injuries such as thermal injuries. Therefore, more detailed study regarding the vertical impact should be conducted.

\section{Conclusion}

Although the caudocephalad impacts (CCI) resulted in large numbers of injuries and deaths, little was known for the CCIinduced thoracoabdomen injuries. A total of 21 adult minipigs were used to carry out the CCI experiments to study the thoracoabdomen injuries, with a modified deceleration sled equipment at the configured speeds. In the present study, the kinematics and mechanical response of the tested animals were analyzed at the different impact speeds. The vital signs and arterial blood gas analysis (ABGA) of the animals were examined. The thoracoabdominal organs, such as the spleen, lung, heart, and spine, were injured frequently, but no liver injury was detected, and the common injuries included fractures, contusion, laceration, bleeding, and hemorrhage. The results presented here may be useful in forensic science, emergency management, and injury prevention.

\section{Conflicts of Interest}

The authors declare that they have no conflicts of interest.

\section{Authors' Contributions}

Sishu Guan and Zhikang Liao contributed equally to this work.

\section{Acknowledgments}

The work was supported by the Logistics Research Project of PLA (BWS13L019, BWS12J033) and partly sponsored by the National Natural Science Foundation of China (no. 31470913).

\section{References}

[1] M. J. Van der Horst, C. K. Simms, R. Van Maasdam, and P. J. C. Leerdam, Occupant Lower Leg Injury Assessment in Landmine Detonations under a Vehicle, Springer, Netherlands, 2005.

[2] B. D. Owens, J. F. Kragh Jr, J. C. Wenke, J. Macaitis, C. E. Wade, and J. B. Holcomb, "Combat wounds in Operation Iraqi Freedom and Operation Enduring Freedom," The Journal of Trauma: Injury, Infection, and Critical Care, vol. 64, no. 2, pp. 295-299, 2008.

[3] J. Alvarez, "Epidemiology of blast injuries in current operations," in A Survey of Blast Injury Across the Full Landscape of Military Science, NATO Science and Technology Organization, Keynote KN1, Halifax, Canada, 2011.

[4] D. Richter, M. P. Hahn, P. A. W. Ostermann, A. Ekkernkamp, and G. Muhr, "Vertical deceleration injuries: a comparative study of the injury patterns of 101 patients after accidental and intentional high falls," Injury, vol. 27, no. 9, pp. 655-9, 1996.

[5] G. Li and S. P. Baker, "Correlates of pilot fatality in general aviation crashes," Aviation, Space, and Environmental Medicine, vol. 70, no. 4, pp. 305-309, 1999.

[6] S. Goren, M. Subasi, Y. Týrasci, and F. Gurkan, "Fatal falls from heights in and around Diyarbakir, Turkey," Forensic Science International, vol. 137, no. 1, pp. 37-40, 2003.

[7] A. Kent and A. Pearce, "Review of morbidity and mortality associated with falls from heights among patients presenting to a major trauma centre," Emergency Medicine Australasia, vol. 18, no. 1, pp. 23-30, 2006.

[8] A. Dickinson, M. Roberts, A. Kumar, A. Weaver, and D. J. Lockey, "Falls from height: injury and mortality," Journal of the Royal Army Medical Corps, vol. 158, no. 2, pp. 123-127, 2012.

[9] M. S. Adams, I. P. Curry, and S. J. Gaydos, "British army air corps accidents, 1991-2010: a review of contrasting decades," Aviation, Space, and Environmental Medicine, vol. 85, no. 8, pp. 852-856, 2014.

[10] V. Jain, S. Jain, and B. K. Dhaon, "A multi factorial analysis of the epidemiology of injuries from falls from heights," 
International Journal of Critical Illness and Injury Science, vol. 4, no. 4, pp. 283-287, 2014.

[11] B. T. Stewart, R. Lafta, S. A. E. al Shatari et al., "Fall injuries in Baghdad from 2003 to 2014: results of a randomised household cluster survey," Injury, vol. 47, no. 1, pp. 244-249, 2016.

[12] J. P. Stapp, "Human tolerance to deceleration; summary of 166 runs," Journal of Aviation Medicine, vol. 22, no. 1, pp. 42-45, 1951.

[13] C. Conroy, J. C. Russell, W. E. Crouse, T. R. Bender, and J. A. Holl, "Fatal occupational injury related to helicopters in the United States 1980-1985," Aviation, Space, and Environmental Medicine, vol. 63, no. 1, pp. 67-71, 1992.

[14] P. D. Tomczak and J. E. Buikstra, "Analysis of blunt trauma injuries: vertical deceleration versus horizontal deceleration injuries," Journal of Forensic Sciences, vol. 44, no. 2, pp. 253262, 1999.

[15] D. A. Wiegmann and N. Taneja, "Analysis of injuries among pilots involved in fatal general aviation airplane accidents," Accident Analysis \& Prevention, vol. 35, no. 4, pp. 571-577, 2003.

[16] B. Liu, H. Ma, and S. Jiang, "Dynamic responses to landing impact at different key segments in selected body positions," Aerospace Science and Technology, vol. 12, no. 4, pp. 331336, 2008.

[17] J. Wang, R. Bird, R. Swinton, and A. Krstic, "Protection of lower limbs against floor impact in army vehicles experiencing landmine explosion," Journal of Battlefield Technology, vol. 4, pp. 8-12, 2001.

[18] S. Tan and K. Porter, "Free fall trauma," Trauma, vol. 8, no. 3, pp. 157-167, 2006.

[19] A. Ramasamy, S. D. Masouros, N. Newell et al., "In-vehicle extremity injuries from improvised explosive devices: current and future foci," Philosophical Transactions of the Royal Society B: Biological Sciences, vol. 366, no. 1562, pp. 160-170, 2010.

[20] R. S. Salzar, J. R. Bolton, J. R. Crandall, G. R. Paskoff, and B. S. Shender, "Ejection injury to the spine in small aviators: sled tests of manikins vs. post mortem specimens," Aviation, Space, and Environmental Medicine, vol. 80, no. 7, pp. 621-628, 2009.

[21] N. Yoganandan, B. D. Stemper, F. A. Pintar, and D. J. Maiman, "Use of postmortem human subjects to describe injury responses and tolerances," Clinical Anatomy, vol. 24, no. 3, pp. 282-293, 2011.

[22] H. A. Pietsch, K. E. Bosch, D. R. Weyland et al., "Evaluation of WIAMan technology demonstrator biofidelity relative to subinjurious PMHS response in simulated under-body blast events," Stapp Car Crash Journal, vol. 60, pp. 199-246, 2016.

[23] A. Tamura, K. Omori, K. Miki, J. B. Lee, K. H. Yang, and A. I. King, "Mechanical characterization of porcine abdominal organs," Stapp Car Crash Journal, vol. 46, pp. 55-69, 2002.

[24] T. A. Gennarelli and E. Wodzin, The abbreviated injury scale 2005 : update 2008, Association for the Advancement of Automotive Medicine, Barrington, 2008.

[25] K. L. Moore, A. M. R. Agur, and A. F. Dalley II, Essential Clinical Anatomy, Wolters Kluwer Health/Lippincott Williams \& Wilkins, 4th ed edition, 2015.

[26] S. Rajasekaran, R. M. Kanna, and A. P. Shetty, "Management of thoracolumbar spine trauma: an overview," Indian Journal of Orthopaedics, vol. 49, no. 1, pp. 72-82, 2015.

[27] M. Franklyn and P. V. S. Lee, Military Injury Biomechanics, CRC Press, Boca Raton, 2017.
[28] A. M. Bailey, J. J. Christopher, F. Brozoski, and R. S. Salzar, "Post mortem human surrogate injury response of the pelvis and lower extremities to simulated underbody blast," Annals of Biomedical Engineering, vol. 43, no. 8, pp. 1907-1917, 2015.

[29] T. C. Atanasijevic, V. M. Popovic, and S. D. Nikolic, "Characteristics of chest injury in falls from heights," Legal Medicine, vol. 11, Supplement 1, pp. S315-S317, 2009.

[30] L. R. Folio, H. T. Harcke, and S. A. Luzi, "Aircraft mishap investigation with radiology-assisted autopsy: helicopter crash with control injury," Aviation, Space, and Environmental Medicine, vol. 80, no. 4, pp. 400-4, 2009.

[31] H. M. Kwon, S. H. Kim, J. S. Hong, W. J. Choi, R. Ahn, and E. S. Hong, "Pelvic bone fractures associated with intraabdominal solid organ injury," Ulusal Travma ve Acil Cerrahi Dergisi, vol. 20, no. 2, pp. 113-119, 2014.

[32] A. J. Davidson, R. M. Russo, S. A. E. Ferencz et al., "A novel model of highly lethal uncontrolled torso hemorrhage in swine," Journal of Surgical Research, vol. 218, pp. 306-315, 2017.

[33] R. M. Russo, T. K. Williams, J. K. Grayson et al., "Extending the golden hour: partial resuscitative endovascular balloon occlusion of the aorta in a highly lethal swine liver injury model," Journal of Trauma and Acute Care Surgery, vol. 80, no. 3, pp. 372-380, 2016.

[34] M. J. Duggan, A. Y. Mejaddam, J. Beagle et al., "Development of a lethal, closed-abdomen grade $\mathrm{V}$ hepato-portal injury model in non-coagulopathic swine," Journal of Surgical Research, vol. 182, no. 1, pp. 101-107, 2013.

[35] J. D. Ross, C. J. Burns, E. M. Sagini, L. A. Zarzabal, and J. J. Morrison, "A laparoscopic swine model of noncompressible torso hemorrhage," Journal of Trauma and Acute Care Surgery, vol. 77, no. 3, pp. S77-S82, 2014.

[36] K. Horst, F. Hildebrand, R. Pfeifer et al., "Impact of haemorrhagic shock intensity on the dynamic of alarmins release in porcine poly-trauma animal model," European Journal of Trauma and Emergency Surgery, vol. 42, no. 1, pp. 67-75, 2016.

[37] D. D. Jewelewicz, S. M. Cohn, B. A. Crookes, and K. G. Proctor, "Modified rapid deployment hemostat bandage reduces blood loss and mortality in coagulopathic pigs with severe liver injury," The Journal of Trauma: Injury, Infection, and Critical Care, vol. 55, no. 2, pp. 275-281, 2003.

[38] M. Wahl, E. M. Gadžijev, J. Wahl, D. Ravnik, J. Pečar, and A. Pleskovič, "An experimental model of reproducible liver trauma," Injury, vol. 36, no. 8, pp. 963-969, 2005.

[39] F. Hildebrand, M. Weuster, P. Mommsen et al., "A combined trauma model of chest and abdominal trauma with hemorrhagic shock-description of a new porcine model," Shock, vol. 38, no. 6, pp. 664-670, 2012.

[40] V. K. Lau and D. C. Viano, "Influence of impact velocity on the severity of nonpenetrating hepatic injury," The Journal of Trauma: Injury, Infection, and Critical Care, vol. 21, no. 2, pp. 115-123, 1981.

[41] V. K. Lau and D. C. Viano, "An experimental study on hepatic injury from belt-restraint loading," Aviation, Space, and Environmental Medicine, vol. 52, no. 10, pp. 611-617, 1981.

[42] J. L. Sparks, Bolte JH 4th, R. B. Dupaix et al., "Using pressure to predict liver injury risk from blunt impact," Stapp Car Crash Journal, vol. 51, pp. 401-432, 2007.

[43] M. A. Kremer, H. M. Gustafson, J. H. Bolte 4th, J. Stammen, B. Donnelly, and R. Herriott, "Pressure-based abdominal 
injury criteria using isolated liver and full-body post-mortem human subject impact tests," Stapp Car Crash Journal, vol. 55, pp. 317-350, 2011.

[44] R. Ramachandra, Y. S. Kang, J. H. Bolte 4th et al., "Biomechanical responses of PMHS subjected to abdominal seatbelt loading," Stapp Car Crash Journal, vol. 60, pp. 59-87, 2016.

[45] E. Samuel, "Deceleration injuries of heart and lungs," Postgraduate Medical Journal, vol. 39, no. 458, pp. 695-704, 1963.

[46] D. Manos, O. Hamer, and N. L. Müller, "Pulmonary hemorrhage resulting from bungee jumping," Journal of Thoracic Imaging, vol. 22, no. 4, pp. 358-359, 2007.

[47] R. R. Burton and W. F. MacKenzie, "Cardiac pathology associated with high sustained +Gz: I. Subendocardial hemorrhage," Aviation Space and Environmental Medicine, vol. 47, no. 7, pp. 711-7, 1976.

[48] Y. Bunai, H. Komoriya, M. Iwasa, and I. Ohya, "Subendocardial hemorrhage of the left ventricle-a study of medicolegal autopsy cases," Nihon Höigaku Zasshi, vol. 42, no. 3, pp. 340-344, 1988.

[49] I. I. Pigolkin and O. V. Dolzhanskiü, "Forensic medical assessment of subendocardial hemorrhage in acute blood loss," Sudebno-Meditsinskaia Ekspertiza, vol. 50, no. 2, pp. 3-5, 2007.

[50] W. Charaschaisri, K. Jongprasartsuk, S. Rungruanghiranya, and L. Kaufman, "Forensic aspect of cause of subendocardial hemorrhage in cardiopulmonary resuscitation cases: chest compression or adrenaline," The American Journal of Forensic Medicine and Pathology, vol. 32, no. 1, pp. 58-60, 2011. 